\title{
STOMACH
}

\section{Sonic hedgehog expression correlates with fundic gland differentiation in the adult gastrointestinal tract}

\author{
G R van den Brink, J C H Hardwick, C Nielsen, C Xu, F J ten Kate, J Glickman, \\ S J H van Deventer, D J Roberts, M P Peppelenbosch
}

See end of article for authors' affiliations

Correspondence to

$G$ van den Brink, Lab Exp

Internal Medicine, Room

G2-130, Academic

Medical Centre,

Meibergdreef 9, $1105 \mathrm{AZ}$,

Amsterdam, the

Netherlands:

g.r.vandenbrink@amc.uva.nl

Accepted for publication

5 March 2002

\begin{abstract}
Background: Sonic hedgehog (Shh) is an important endodermal morphogenetic signal during the development of the vertebrate gut. It controls gastrointestinal patterning in general, and gastric gland formation in particular. We have previously shown that Shh regulates gastric gland proliferation in the adult but detailed analysis of its expression along the adult gastrointestinal tract has never been undertaken. We therefore studied Shh expression along the normal human and rodent adult gastrointestinal tract as well as in intestinal metaplasia of the stomach, gastric and intestinal metaplasia of the oesophagus, and gastric heterotopia in Meckel's diverticulum.

Methods: The studies were performed with in situ hybridisation and by immunohistochemistry using an antibody that recognises the Shh precursor form.

Results: We found that in the normal gastrointestinal tract, high levels of Shh were expressed in the fundic glands of the stomach. Shh expression was also found in fundic gland metaplasia and heterotopia. However, Shh expression was lost in intestinal metaplasia of the stomach.

Conclusion: We found a strong correlation between Shh expression and fundic gland differentiation. Our current study therefore provides evidence that in addition to its role in gastric epithelial development, Shh plays a unique role in gastric epithelial differentiation in adults.
\end{abstract}

D uring organogenesis, the cells of the endodermal layer give rise to the liver, pancreas, and epithelial cells of the lung and gastrointestinal tract. Differentiation of these different organs with their respective functional cell types occurs through complex mesenchymal-endodermal interaction. In this interaction, the hedgehog $(\mathrm{Hh})$, fibroblast growth factor, Wnt, and transforming growth factor $\beta$ families of secreted proteins play a key role.

Hh was initially identified in a genetic screen for segment polarity genes in Drosophila. ${ }^{2}$ In vertebrates, three hedgehog genes have been identified, sonic hedgehog (Shh), Indian hedgehog, and desert hedgehog. All three Hhs bind to the same receptor (patched) which controls the activity of a second receptor (smoothened). ${ }^{3}$ Both Shh and Indian hedgehog play a role in endodermal/ectodermal-mesodermal interactions in the gut. ${ }^{4-14}$

Expression of Shh in the gastrointestinal tract has been described during development in many vertebrate systems, including the mouse, ${ }^{4}$ chick, ${ }^{5}$ human, ${ }^{13}$ and frog. ${ }^{14}$ In all species examined, Shh is expressed from the earliest time points of gastrointestinal development, restricted in its expression to the endoderm. The murine gut has been widely examined for Shh mRNA expression throughout development. At a late stage of development, 18.5 days post coitus, one day prior to birth, Shh mRNA is detected in the glandular epithelium of the stomach, small intestine, and colon. ${ }^{9}$ However, although this is a late stage of intrauterine development, the murine gastrointestinal tract undergoes major morphological and functional changes during the first three postnatal weeks, including formation of intestinal crypts and maturation of the gastric glands. ${ }^{15}{ }^{16}$ It is therefore difficult to infer from these data what happens to Shh mRNA expression in the adult.

Several studies have addressed the functional role of Shh expression in the developing gut. Studies in chick and mouse using either overexpression or inactivation of Shh suggest that during development, Shh is a critical endodermal signal in the epithelial-mesodermal signalling involved in specification of differentiation along the anterior-posterior as well as the radial axis of the vertebrate gut..$^{5-14}$ Shh null mice display gastrointestinal malformations, including failure of the trachea and oesophagus to separate normally, ${ }^{7}$ gut malrotation, and small intestinal and anus atresias. ${ }^{9}$ The gastric epithelium of Shh null mice shows epithelial hyperplasia and alkaline phosphatase expression, a sign of intestinal differentiation. ${ }^{9}$ The critical role of Shh in gastric epithelial development is further supported by the finding that the Hh inhibitor cyclopamine causes pancreatic transformation of the stomach in embryonic chicks. ${ }^{10}$

The lack of information on Hh expression in the adult is unfortunate as these proteins are likely to play an important role in the orchestration of the complex patterns of epithelial proliferation and differentiation in this rapidly regenerating system. Since Shh is an important polarising signal during development, we previously investigated whether Shh is involved in the maintenance of asymmetry of epithelial differentiation in the tubular units of the adult fundic stomach. ${ }^{17}$ In this part of the gut the stem cell is located in the midportion or isthmus of the tubular unit. From the isthmus cells migrate either up towards the lumen and become mucin (MUC)5AC expressing pit cells or migrate downwards to become one of the cell types of the fundic gland (mucous neck cell, parietal cell, zymogenic/chief cell, endocrine cell, and caveolated cell). ${ }^{18}$ We showed that Shh is expressed in the fundic gland of the adult human and rodent stomach. Inhibition of Shh led to enhanced epithelial proliferation and diminished protein levels of bone morphogenic protein 4, islet-l, and hepatocyte nuclear factor $3 \beta$, all of which are proteins involved in differentiation and tissue specific gene expression. ${ }^{17}$ Thus Shh appears to be involved in the regulation of gastrointestinal epithelial homeostasis in the adult but systematic

Abbreviations: Hh, hedgehog; Shh, sonic hedgehog; MUC, mucin; PBS, phosphate buffered saline; strep $\beta$-gal, streptavidin $\beta$-galactosidase; $H H G$, hyperplastic hypersecretory gastropathy. 

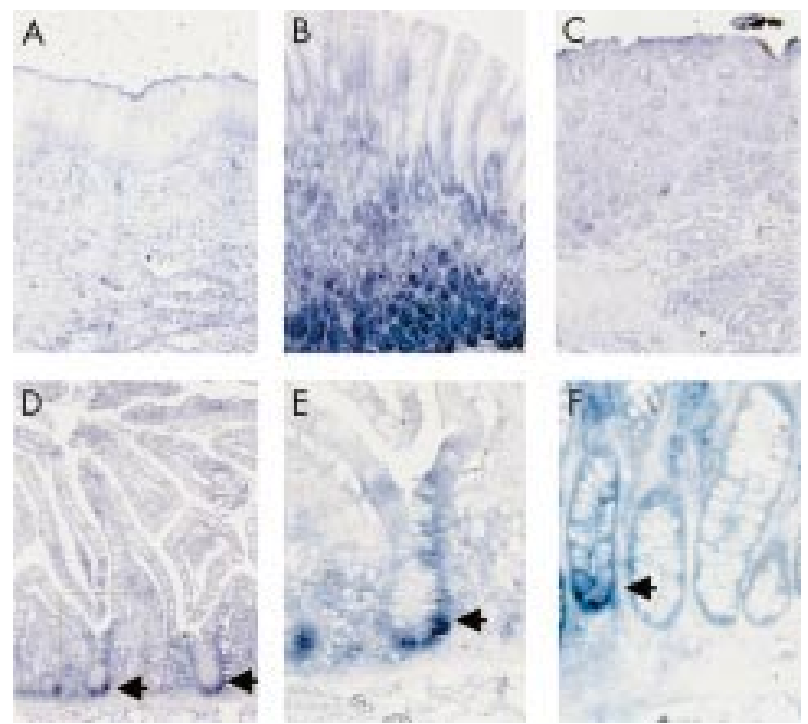

Figure 1 Sonic hedgehog (Shh) mRNA expression along the human gastrointestinal tract. Shh expression was detected (blue stain) in the fundic glandular region (B) of the adult stomach. Shh was not detected in the oesophagus $(A)$ or the antrum of the stomach (C). A few positive cells were found at the base of the crypts in the small intestine (arrows in D and in blow up of boxed area in E) and some of the crypts of the colon (F, arrow).

study of expression of Shh along the adult gastrointestinal tract has not been performed.

Because of the important role of Shh in intestinal development it is important to know if Shh expression is specific for the fundic glands or also occurs in other tissues along the gastrointestinal tract. These considerations prompted us to investigate the expression pattern of Shh along the adult human and murine gastrointestinal tract. As loss of Shh expression in the developing stomach results in intestinal or pancreatic transformation of the gastric epithelium, we also examined intestinal metaplasia of the adult stomach for possible loss of Shh expression. Thereafter we examined Shh expression in ectopic fundic glands of both developmental origin (heterotopia) and postnatal origin (metaplasia). Our studies identify Shh as a fundic gland specific protein and thus provide important evidence for a unique role of the Shh morphogen in fundic gland homeostasis.

\section{METHODS}

\section{Antibodies}

A goat polyclonal $\alpha$-Shh antibody (N-19, 1:250) produced by immunising with an amino acid sequence mapping at the amino terminus of the murine Shh precursor was obtained from Santa Cruz Biotechnology (Santa Cruz, California, USA). We have shown previously that this antibody specifically recognises the $49 \mathrm{kDa}$ Shh precursor protein. ${ }^{17} \mathrm{~A}$ mouse monoclonal $\alpha-\mathrm{H}^{+} / \mathrm{K}^{+}$-ATPase (1:6000) was from Affinity Bioreagents (Golden, Colorado, USA). A mouse monoclonal anti-MUC5AC (1:50, clone 45Ml) was from Lab Vision (Fremont, California, USA). A mouse monoclonal anti-MUC2 (1:100, clone CCP58) was from Novocastra (Newcastle upon Tyne, UK).

\section{Tissues}

To study Shh expression in the human gastrointestinal tract we used specimens from the archives of the Department of Pathology of the Academic Medical Centre and the Department of Pathology of the Massachusetts General Hospital and Brigham and Women's Hospital. We examined tissue with normal histology from at least 10 different patients to investigate each site along the normal gastrointestinal tract for Shh expression. Other specimens included: tissue from 16 different patients with intestinal metaplasia of the stomach, 13 resection specimens of Meckel's diverticulum, and six resection specimens of patients with Barrett's oesophagus.

\section{In situ hybridisation}

Human Shh cDNA, a gift from Dr C Tabin, was used to transcribe a digoxigenin labelled (Roche, Mannheim, Germany) mRNA probe, as previously described. ${ }^{13}$ Paraffin sections (4-6 $\mu \mathrm{m})$ of archival human tissue were used for in situ hybridisation using previously published methods. ${ }^{13}$

\section{Immunohistochemistry}

Methods used for staining of a single epitope on paraffin sections have been described in detail previously. ${ }^{17}{ }^{19}$ For double staining of Shh and MUC5AC, sections were incubated with a mixture of the anti-Shh and anti-MUC5AC overnight. The following day, sections were incubated with a mixture of horseradish peroxidase coupled rabbit antigoat Ig (1:100, Dako, Glostrup, Denmark) and biotinylated rabbit antimouse Ig ( $1: 250)$. Firstly, horseradish peroxidase was detected with fast DAB, as described previously, ${ }^{17}{ }^{19}$ and thereafter sections were incubated with streptavidin $\beta$-galactosidase (strep $\beta$-gal, 1:50 in phosphate buffered saline (PBS); Roche, Almere, the Netherlands) for 30 minutes at room temperature. $\beta$-Gal was detected with $40 \mu \mathrm{g} / \mathrm{ml} \mathrm{X-Gal} \mathrm{(Gibco,} \mathrm{Breda,} \mathrm{the} \mathrm{Netherlands)}$ in iron phosphate buffer $\left(0.02 \% \mathrm{MgCl}_{2} \cdot 6 \mathrm{H}_{2} \mathrm{O}, 0.099 \%\right.$ potassium ferricyanide, $0.127 \%$ potassium ferrocyanide) at $37^{\circ} \mathrm{C}$ for 15 minutes, resulting in a turquoise colour.

Simultaneous immunohistochemical detection of three different epitopes was performed, largely as described previously. ${ }^{19}$ For triple staining of Shh, MUC5AC, and MUC2, the following protocol was developed. Sections were rehydrated and blocked as described and incubated with the antiMUC5AC monoclonal overnight. The following day, sections were incubated with an alkaline phosphatase coupled goat antimouse Ig ( $1: 20$, Dako) in PBS containing 10\% human AB serum for one hour. After washing in Tris buffered saline, alkaline phosphatase activity was detected using Fast Red (Dako) resulting in a red precipitate. Thereafter sections were heated to $100^{\circ} \mathrm{C}$ for five minutes to remove antibodies and enhance antigen retrieval for the anti-Shh antibody. Sections were blocked and incubated with a mixture of monoclonal anti-MUC2 and goat polyclonal anti-Shh overnight. On day 3, sections were incubated with a mixture of rabbit antimousehorseradish peroxidase (1:50) and rabbit antigoat-biotin ( $1: 200)$ in PBS containing 10\% human AB serum for one hour. Firstly, horseradish peroxidase was detected with DAB, as described above, and thereafter sections were incubated with strep $\beta$-gal for 30 minutes at room temperature. $\beta$-gal was detected as above. We used three different negative controls: omission of the anti-Shh antibody, control Ig, and an anti-Shh blocking peptide (Santa Cruz). As a positive control we used embryonic tissues of both chick and zebrafish.

\section{RESULTS}

\section{Fundic glands express high levels of Shh protein}

We have previously shown that Shh protein is expressed in the fundic glands of humans and rodents. ${ }^{17}$ We have now examined the length of the human gastrointestinal tract for both Shh mRNA and protein expression. In the adult gastrointestinal tract, Shh mRNA was abundantly expressed in the fundic part of the stomach and we also detected a few positive cells at the base of the crypts in the small intestine and colon (as has been described in the human fetus, see Marigo and colleagues $^{13}$ ) (fig 1). Whereas each crypt contained such cells in the small intestine, in the colon these cells were found in fewer crypts. To investigate expression of Shh protein we used an antibody that recognises the Shh precursor protein. ${ }^{17}$ In the human, mouse, and rat gastrointestinal tract, Shh staining 


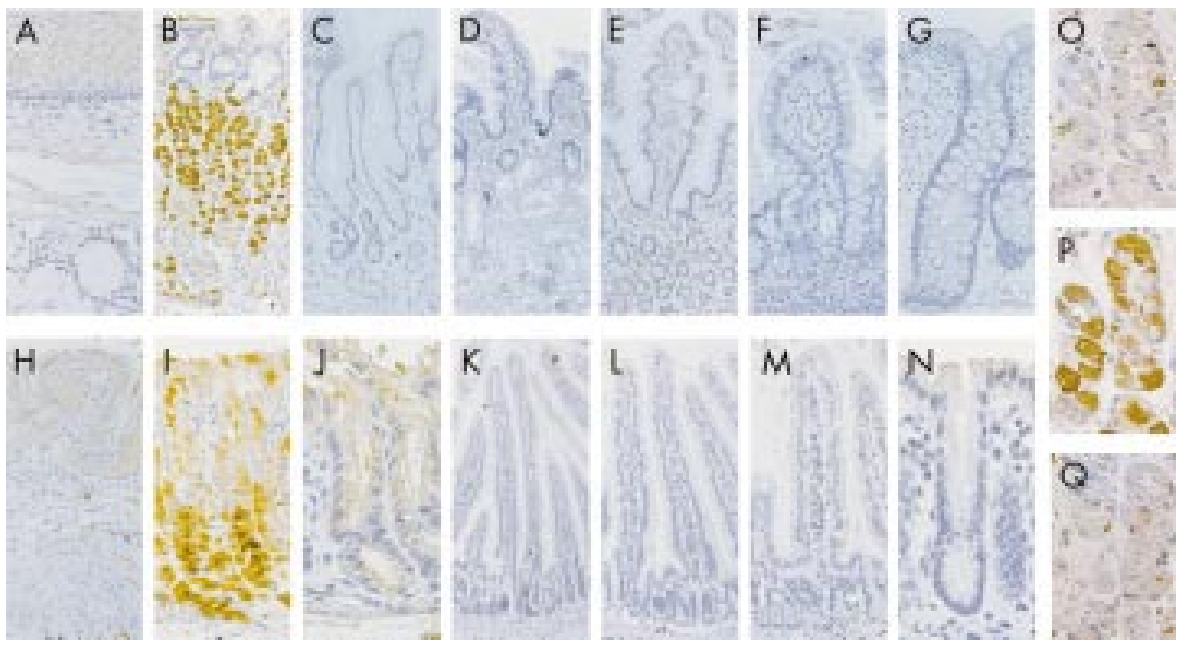

Figure 2 Sonic hedgehog (Shh) protein expression along the human and murine gastrointestinal tract. (A-G) Sections of the human gastrointestinal tract; immunohistochemical staining with an antibody against the Shh precursor protein. We found intense staining in the fundic glands (B) whereas no staining was found in the oesophagus $(A)$, antrum $(C)$, Brunner's glands (D), duodenum (E), ileum (F), or colon (G). Sections of the murine gastrointestinal tract $(\mathrm{H}-\mathrm{N})$ gave the same results. Shown are: forestomach $(\mathrm{H})$, fundic glands (I), antral glands (J), duodenum $(K)$, jejunum (L), ileum $(M)$, and colon $(N)$. Control experiments in three adjacent sections are also shown (O-Q). No signal was found in the human fundic gland with isotype control antibody (O) and the signal detected with the anti-Shh antibody (P) was efficiently blocked with a blocking peptide $(Q)$.

was exclusively detected in the fundic glands of the stomach. In contrast, no Shh staining was observed in the oesophagus or in the intestine (fig 2). Omission of the primary antibody or use of control Ig did not result in any visible staining, and staining with the anti-Shh antibody was efficiently blocked with the blocking peptide. The anti-Shh antibody reacted with endoderm of both chick and zebrafish used as positive controls (not shown).

\section{Shh expression is lost in intestinal metaplasia of the fundus}

During development of the stomach, absence of Shh leads to intestinal transformation of the stomach.' In humans, replacement of gastric epithelium by epithelium of the intestinal phenotype, or intestinal metaplasia, is commonly observed in patients with chronic gastritis. This metaplasia is an important risk factor for the development of gastric adenocarcinoma. ${ }^{20}$ To evaluate the possibility that alterations in Shh expression may be involved in intestinal metaplasia in humans, we studied whether Shh expression is lost in intestinal metaplasia of the fundic gland region. To optimally localise Shh expression relative to intestinal metaplasia in these specimens, we used an immunohistochemical triple staining method. This method visualises cytoplasmic and extracellular MUC5AC, the mucin produced by gastric pit cells, ${ }^{19}$ cytoplasmic MUC2, a mucin specifically expressed by the goblet cells of the intestine, ${ }^{21}$ and Shh. This triple stain has an additional advantage that intestinal absorptive enterocytes are readily identified in specimens with intestinal metaplasia due to the typical thin staining of the brush border that contains intestinal alkaline phosphatase.

No overlap between MUC5AC and Shh was found as MUC5AC marks pit cells that migrate up from the precursor cell and Shh is exclusively expressed by the downward migrating parietal cells of the gastric glands. ${ }^{17}$ Using this method we found that expression of Shh and MUC2 was mutually exclusive in all specimens investigated $(n=16)$. This clearly demonstrates that in areas of intestinal metaplasia Shh expression is completely lost.

Although not the primary aim of our study, we were also able to identify three types of intestinal metaplasia on the basis of mucin expression in specimens that allowed good visualisation of the full gastric unit. The first type was characterised by MUC2 positive goblet cells and intestinal-type absorptive cells with an alkaline phosphatase positive brush border (see unit marked with an asterisk in fig 3D). In the second type, only gland cells were replaced by MUC2 expressing goblet cells whereas pit cells where still of the MUC5AC expressing gastric phenotype (see fig $3 \mathrm{~A}-\mathrm{C}$ ). In the third type the gland contained MUC2 positive goblet cells whereas the pit consisted of a mix of MUC5AC expressing pit cells and MUC2 positive goblet cells (see unit marked with an arrow in fig 3D). Similar to findings described in two previous reports on metaplasias, ${ }^{22}{ }^{23}$ three types of goblet cells were observed in this study. Most goblet cells were found to express MUC2 exclusively (fig 3E) as is the case in a normal intestinal goblet cell $^{21}$ but we also found more rarely that goblet cells displayed exclusive expression of MUC5AC (fig 3G) or coexpressed MUC2 and MUC5AC (fig 3F). MUC2-MUC5AC coexpressing goblet cells were found in the region of the isthmus whereas goblet cells that had migrated further from here were invariably found to express only MUC2, indicating a transition from a mixed gastric-intestinal to a purely intestinal phenotype.

\section{Shh is expressed in fundic gland heterotopia}

To investigate if Shh is expressed in gastric heterotopia of the small intestine, we examined human resection specimens of Meckel's diverticulum $(n=13)$. Meckel's diverticulum is a common abnormality of the small intestine that occurs in $1-3 \%$ of the population. ${ }^{24}$ This remnant of the omphalomesenteric duct often contains heterotopic tissue of various endodermal derivatives. We stained all specimens examined for both the $\mathrm{H}^{+} \mathrm{K}^{+}$ATPase to identify acid producing parietal cells of the fundic gland and for Shh. All specimens that contained parietal cells $(n=8)$ were also positive for Shh (fig $4 B$, C) whereas specimens that lacked fundic glands (four with intestinal and one with antral mucosa) also lacked Shh staining (fig 4A). Thus Shh is expressed in fundic gland heterotopia, indicating that aberrant development of intestinal epithelium into gastric epithelium with fundic glands is accompanied by shh expression.

\section{Shh is expressed in fundic gland metaplasia of the oesophagus}

In patients with chronic acid reflux the resulting inflammation of the oesophagus can lead to columnar metaplasia of the normally squamous epithelium of the oesophagus, a condition called Barrett's oesophagus. While these patients frequently 

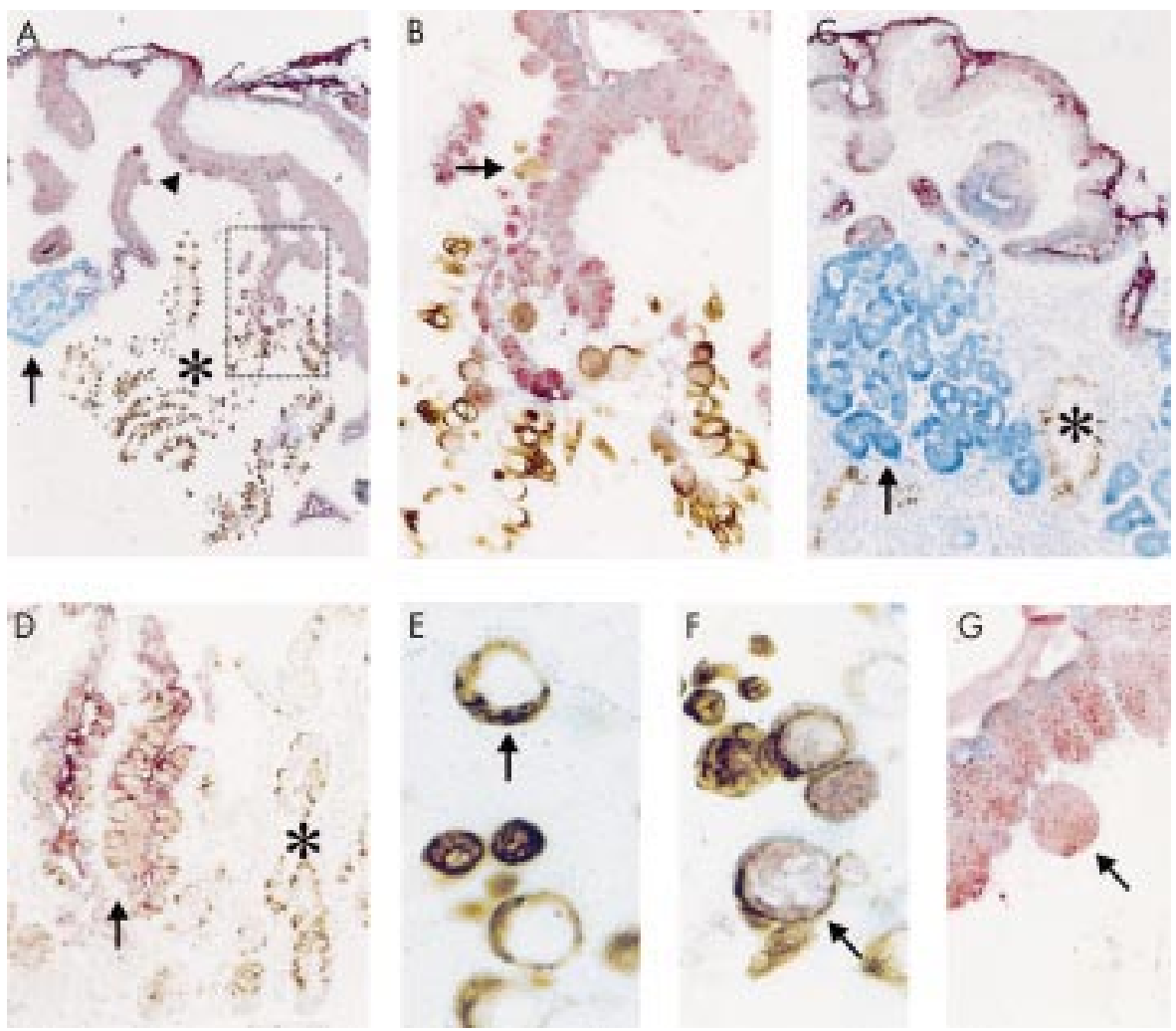

Figure 3 Sonic hedgehog (Shh) expression was lost in intestinal metaplasia of the stomach. Immunohistochemical triple stain of Shh (blue), mucin (MUC)5AC (red), and MUC2 (brown). (A-C) Specimens of two different patients with intestinal metaplasia. (A) This specimen shows normal glands with MUC5AC expressing pit cells (arrowhead, red stain), Shh expressing gland cells (arrow, blue stain), and adjacent metaplastic glands with MUC2 expressing goblet cells (asterisk, brown stain). (B) Blow up of boxed area in (A); note MUC5AC expression by goblet cells around the pit gland transition. (C) Another example of metaplastic gland (asterisk) amid normal Shh expressing glands (arrow). (D) Although most cases showed replacement of only the glands or both pits and glands by intestinal cells, in this patient we observed a mix of intestinal MUC2 expressing goblet cells (brown) and gastric MUC5AC expressing pit cells (red) in the pit region. (E-G) Three types of goblet cells were observed in this study: goblet cells that expressed exclusively MUC2 (arrow in E), goblet cells that coexpressed MUC2 and MUC5AC (arrow in F), and goblet cells that expressed only MUC5AC (arrow in G).
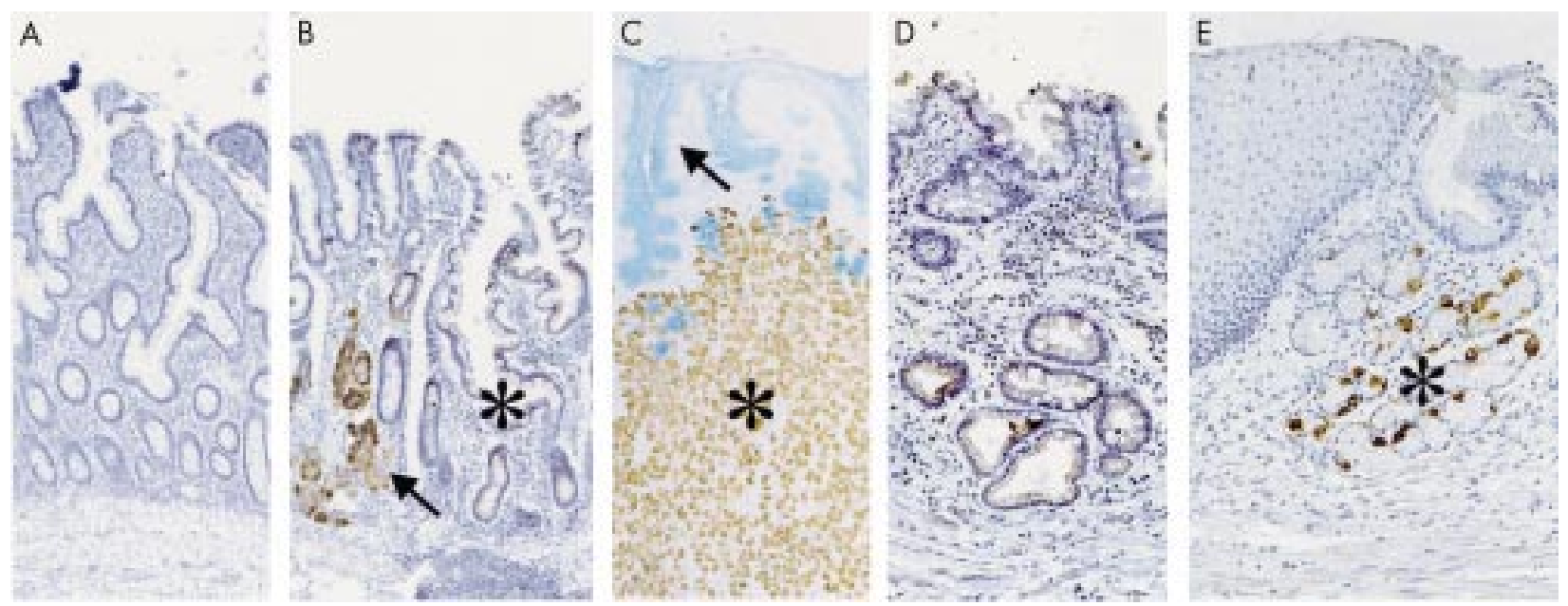

Figure 4 Sonic hedgehog (Shh) was expressed in fundic gland ectopies. (A-C) Three different cases of Meckel's diverticulum. (A) No Shh was detected in a Meckel's specimen with purely intestinal histology. (B) Shh staining (brown precipitate, arrow) in a gastric fundic gland adjacent to a region of goblet cell containing intestinal histology (asterisk). (C) Double stain of the gastric mucin MUC5AC (blue, arrow) and Shh (brown, asterisks) in a Meckel's diverticulum with fundic gland histology. (D, E) Oesophageal metaplasias. (D) No Shh was detected in the intestinal metaplasia of Barrett's mucosa. (E) A case of fundic gland metaplasia of the oesophagus with Shh expressing cells (brown precipitate, asterisk).

develop intestinal metaplasia in the columnar lined segment, a mixture of gastric and intestinal-type epithelium is commonly observed. ${ }^{25}$ To see if Shh expression is also induced postnatally in areas of gastric metaplasia, we examined oesophageal resection specimens of six patients with Barrett's oesophagus for expression of both the $\mathrm{H}^{+} \mathrm{K}^{+}$ATPase and Shh. We found one resection specimen with areas of gastric metaplasia of fundic type glands. Complete overlap of $\mathrm{H}^{+} \mathrm{K}^{+}$ATPase expression and Shh expression was found in this specimen (fig 4E) whereas all oesophageal (including the submucosal 
glands) and intestinal tissue in the resection specimens were negative for Shh (fig 4D). This indicates that the switch in differentiation from squamous to gastric epithelial tissue with fundic glands is accompanied by induction of Shh expression.

\section{DISCUSSION}

Shh is an important endodermal signal in endodermalmesenchymal cross talk during development in both anteriorposterior and radial patterning of the gut tube. Its role in the adult gut is poorly understood. Although we have shown previously that Shh is expressed in the fundic glands of the adult gastrointestinal tract, ${ }^{17}$ expression of Shh along the adult gastrointestinal tract has so far not been specifically described. Herein we have examined its expression in normal tissue and in various conditions characterised by loss and gain of fundic gland differentiation along the gastrointestinal tract. Our data show that Shh protein expression is closely correlated with fundic gland differentiation in the adult.

The stem cells of the glandular stomach are situated approximately halfway up the tubular invaginations that contain the gastric glands. Cells that migrate up from this point (towards the lumen) form the mucus producing or pit cells of the so-called pit region. Cells that migrate down from the stem cell region form the gland proper with a variety of functional cell types. Several independent lines of evidence indicate that there are polarising signals in the gastric units that promote either pit or gland cell proliferation and differentiation. Initial evidence for the existence of polarising signals in the fundic units comes from patients with hypertrophic gastropathies. These gastropathies include Ménétrier disease and hyperplastic hypersecretory gastropathy (HHG). ${ }^{26}$ Massive proliferation and differentiation of pit cells and concomitant loss of glandular epithelial cells characterise Ménétrier disease whereas patients with HHG show an increased mass of gland cells. The pit cell promoting factor that causes Ménétrier disease has been identified as transforming growth factor $\alpha$, a ligand for the epidermal growth factor receptor. ${ }^{27-29}$

Until recently, no glandular epithelial cell type promoting factor had been identified. We have provided evidence that Shh may be a glandular cell promoting factor in gastric epithelial homeostasis. We have previously shown that Shh selectively influences the cell cycle of gastric epithelial gland cells and in this manner may act as a polarising signal. High expression of Shh in the fundic glands in the normal adult human and rodent gastrointestinal tract presented herein supports a specific role for Shh in fundic gland differentiation. Although no Shh protein was detected in the intestine, we found that a few cells at the base of the crypts were positive for Shh mRNA. Thus Shh may be expressed at low levels by a few cells in the crypts of the small intestine and colon but these levels where too low to be detected with the immunohistochemical methodology used in our study.

Apart from the above mentioned patients with HHG, the pathology observed in patients with autoimmune gastritis ${ }^{30}$ provides additional evidence for the existence of a gland cell type promoting factor and suggests that the parietal cell may be the source of this factor. In these patients, autoantibodies against the $\mathrm{H}^{+} \mathrm{K}^{+}$ATPase result in cytotoxic T cell mediated parietal cell depletion. Although most of these patients lack antibodies against epitopes expressed by zymogenic cells, ${ }^{31}$ loss of parietal cells is followed by loss of zymogenic cells, suggesting that parietal cells secrete a factor important for zymogenic cell differentiation. Loss of gland cells in autoimmune gastritis is, in the end, often followed by intestinal metaplasia. A similar histopathology has also been described in parietal cell depleted mice. ${ }^{32}$ Finally, evidence from the mouse suggests that activin antagonises the gland cell type promoting polarising signal. ${ }^{33}$ Mice deficient for $\alpha$-inhibin produce large quantities of activin $\mathrm{A}$ and $\mathrm{B}$. The gastric (epithelial) histology of these mice resembles that of patients with autoimmune gastritis in the parietal cell depleted mouse. The fundic units of these mice show increased amounts of pit cells, loss of parietal cells, and absence of zymogenic cells.

This antagonism of the hypothesised gland cell promoting factor by activin is intriguing in the light of our finding that this factor may be Shh. Activin has been shown to repress Shh expression in Hensen's node during establishment of chick left-right asymmetry, ${ }^{34}$ and notochord derived activin antagonises endodermal Shh expression in the area of the prospective pancreatic buds, ${ }^{11}$ which is essential for the normal development of the pancreas. ${ }^{12}$

In this study we found that epithelial Shh expression mirrored the type of epithelial differentiation observed in several human pathological conditions. Loss of fundic glands in gastric intestinal metaplasia is accompanied by loss of Shh expression whereas ectopic Shh expression is observed in fundic gland metaplasia, supporting the fact that Shh is a fundic gland specific factor. Although gene expression in intestinal metaplasia of the stomach has been extensively characterised, these studies have focused on describing markers of intestinal differentiation that are unlikely to play a controlling role in the conversion of a gastric to an intestinal epithelial phenotype. Silberg et al identified the intestine specific transcription factor $\mathrm{Cdxl}$ as a factor that may play a role in the induction or maintenance of intestinal metaplasia of the oesophagus and stomach. ${ }^{35}$ The present study however is, to the best of our knowledge, the first report of loss of a fundic gland specific soluble morphogen in intestinal metaplasia. It is not clear from these results whether loss of Shh expression precedes or is necessary for the development of intestinal metaplasia. Loss of expression of a morphogen that controls gastric gland morphogenesis may be an initiating step in the sequence of events leading to intestinal metaplasia. There is experimental evidence to support this theory as the Shh null mouse exhibits intestinal metaplasia of the stomach. ${ }^{9}$

In conclusion, we have presented evidence that Shh is a fundic gland specific factor in the normal stomach and in several human diseases characterised by aberrant gastric epithelial differentiation. These results support the hypothesis that Shh may be an essential polarising signal for fundic gland differentiation, an idea supported by the existing literature.

\section{Authors' affiliations}

G R van den Brink, J C H Hardwick, C Xu, M P Peppelenbosch, Department of Experimental Internal Medicine, Academic Medical Centre, Amsterdam, the Netherlands

C Nielsen, D J Roberts, Department of Pediatric Surgery, Massachusetts General Hospital, Brigham and Women's Hospital, Boston, USA F J ten Kate, Department of Pathology, Academic Medical Centre, Amsterdam, the Netherlands

J Glickman, Department of Pathology, Brigham and Women's Hospital, Boston, USA

S J H van Deventer, Department of Gastroenterology, Academic

Medical Centre, Amsterdam, the Netherlands

\section{REFERENCES}

1 Hogan BLM. Morphogenesis. Cell 1999;96:225-33.

2 Nüsslein-Volhard C, Wieschaus E. Mutations affecting segment number and polarity in Drosophila. Nature 1980;287:795-801.

3 Kalderon D. Transducing the hedgehog signal. Cell 2000;103:371-4.

4 Bitgood MJ, MacMahon AP. Hedgehog and Bmp genes are coexpressed at many diverse sites of cell-cell interaction in the mouse embryo. Dev Biol 1995;172:126-38.

5 Roberts DJ, Johnson RL, Burke AC, et al. Sonic hedgehog is an endodermal signal inducing BMP-4 and Hox genes during induction and regionalization of the chick hindgut. Development 1995; 1 18:47-59.

6 Roberts DJ, Smith DM, Goff DJ, et al. Epithelial-mesenchymal signaling during the regionalization of the chick gut. Development 1998;125:2791-801.

7 Litingung $Y$, Lei L, Westphal $\mathrm{H}$, et al. Sonic hedgehog is essential to foregut development. Nat Genet 1998;20:58-61.

8 Sukegawa A, Narita T, Kameda T, et al. The concentric structure of the developing gut is regulated by Sonic hedgehog derived from endodermal epithelium. Development 2000;1 27: 1971-80. 
9 Ramalho-Santos M, Melton DA, McMahon AP. Hedgehog signals regulate multiple aspects of gastrointestinal development. Development 2000; 127:2763-72.

10 Kim SK, Melton DA. Pancreas development is promoted by cyclopamine, a hedgehog signaling inhibitor. Proc Natl Acad Sci U S A 1998;27:13036-41

11 Hebrok M, Kim SK, Melton DA. Notochord repression of endodermal Sonic hedgehog permits pancreas development. Genes Dev 1998;12:1705-13.

12 Apelqvist A, Ahlgren U, Edlund $\mathrm{H}$. Sonic hedgehog directs specialised mesoderm differentiation in the intestine and pancreas. Curr Biol 1997; 7:801-4

13 Marigo V, Roberts DJ, Lee SM, et al. Cloning, expression, and chromosomal location of $\mathrm{SHH}$ and $\mathrm{IHH}$ : two human homologues of the Drosophila segment polarity gene hedgehog. Genomics 1995;28:44-51.

14 Ryan AK, Blumberg B, Rodriguez-Esteban C, et al. Pitx2 determines left-right asymmetry of internal organs in vertebrates. Nature 1998:394:545-51.

15 Gordon JI, Hermiston ML. Differentiation and self-renewal in the mouse gastrointestinal epithelium. Curr Biol 1994;6:795-803.

16 Karam SM, Li Q, Gordon JI. Gastric epithelial morphogenesis in normal and transgenic mice. Am J Physiol 1997;272:G1209-20.

17 Van den Brink GR, Hardwick JCH, Tytgat GNJ, et al. Sonic hedgehog regulates gastric gland morphogenesis in man and mouse. Gastroenterology 2001;121:317-28.

18 Karam SM, Leblond CP. Identifying and counting epithelial cell types in the "corpus" of the mouse stomach. Anat Rec 1992;232:231-46.

19 Van den Brink GR, Tytgat KMAJ, Van der Hulst RW, et al. H. pylori colocalises with MUC5AC in the human stomach. Gut 2000;46:601-7.

20 Stemmermann GN. Intestinal metaplasia of the stomach. A status report. Cancer 1994;74:556-64.

21 Tytgat KMAJ, Büller HA, Opdam FJM, et al. Biosynthesis of human colonic mucin: Muc2 is the most prominent secretory mucin. Gastroenterology 1994;107:1352-63.

22 Reis CA, David L, Correa P, et al. Intestinal metaplasia of human stomach displays distinct patterns of mucin (MUC1, MUC2, MUC5AC, and MUC6) expression. Cancer Res 1999;59:1003-7.
23 Shaoul R, Marcon P, Okada Y, et al. The pathogenesis of duodenal gastric metaplasia: the role of local goblet cell transformation. Gut 2000;46:632-8.

24 Turgeon DK, Barnett JL. Meckel's diverticulum. Am J Gastroenterol 1990;85:777-81.

25 Jankowski JA, Harrison RF, Perry I, et al. Barrett's metaplasia. Lancet 2000;356:2079-85

26 Komorowski RA, Caya JG. Hyperplastic gastropathy. Clinicopathologic correlation. Am J Surg Pathol 1991;15:577-85.

27 Dempsey PJ, Goldenring JR, Soroka CJ, et al. Possible role of transforming growth factor alpha in the pathogenesis of Menetrier's disease: supportive evidence form humans and transgenic mice. Gastroenterology 1992;103:1950-63.

28 Takagi H, Jhappan C, Sharp R, et al. Hypertrophic gastropathy resembling Menetrier's disease in transgenic mice overexpressing transforming growth factor alpha in the stomach. J Clin Invest 1992;90:1161-7.

29 Burdick JS, Chung E, Tanner G, et al. Treatment of Menetrier's disease with a monoclonal antibody against the epidermal growth factor receptor. N Engl J Med 2000;343: 1697-701.

30 Toh BH, Van Driel IR, Gleeson PA. Pernicious anemia. N Engl J Med 1997;337:1441-8.

31 D'Elios MM, Bergman MP, Azzurri A, et al. $\mathrm{H}(+), \mathrm{K}(+)$-atpase (proton pump) is the target autoantigen of Th 1-type cytotoxic T cells in autoimmune gastritis. Gastroenterology 2001;120:377-86.

32 Li Q, Karam SM, Gordon JI. Diphtheria toxin-mediated ablation of parietal cells in the stomach of transgenic mice. J Biol Chem 1996;271:3671-6.

33 Li Q, Karam SM, Coerver KA, et al. Stimulation of activin receptor II signaling pathways inhibits differentiation of multiple gastric epithelial lineages. Mol Endocrinol 1998;12:181-92.

34 Levin $M$, Johnson RL, Stern CD, et al. A molecular pathway determining left-right asymmetry in chick embryogenesis. Cell 1995;82:803-14.

35 Silberg DG, Furth EE, Taylor JK, et al. CDXI protein expression in normal, metaplastic, and neoplastic human alimentary tract epithelium. Gastroenterology 1997;113:478-86. 